\title{
Prediction of Cucumber Harvest Date Using a Heat Unit Model
}

\author{
Katharine B. Perry ${ }^{1}$ and Todd C. Wehner ${ }^{2}$ \\ Department of Horticultural Science, North Carolina State University, \\ Raleigh, NC 27695-7609
}

Additional index words. Cucumis sativus, growing degree days, phenology, vegetable production

Abstract. A heat unit model developed in a previous study was compared to the standard method (average number of days to harvest) for ability to predict harvest date in cucumber (Cucumis sativus L.). Processing and fresh-market cucumbers were evaluated in 3 years (1984 through 1986), three seasons (spring, summer, and fall), and three North Carolina locations. The model predicted harvest date significantly better than the standard method for processing, but not for fresh-market cucumbers.

Cucumbers are widely grown in the United States for processing (pickling) and freshmarket use. The crop is usually harvested by hand six or more times. Some of the processing crop is harvested once-over by machine. The trend is to harvest fewer times, because new cultivars provide a more concentrated fruit set, and harvest costs are becoming a larger part of production costs. Prior prediction of harvest date is important to ensure that fruits are picked at the optimum stage of development. As more production is handled by machine harvest, scheduling of harvest dates will become more critical.

The standard method for scheduling cucumber harvest date is to use number of days from planting to first harvest based on previous years of production. In areas where more than one crop can be grown each year, the estimate must be adjusted according to whether the crop is planted in the spring, summer, or fall.

In a previous study, which included an extensive review of the heat unit literature, 14 methods to determine heat unit requirements for cucumber harvest were compared (Perry et al., 1986). The best method, hereafter referred to as "reduced ceiling," was to sum, over days from planting to harvest, the difference between the daily maximum and a base temperature of $15.5 \mathrm{C}$, but, if the maximum exceeded $32 \mathrm{C}$, it was replaced by $32 \mathrm{C}$ minus the difference between the maximum and 32C, before subtracting the base. Data for the study in which the model was developed were taken from two growing seasons (spring and summer) over 5 years (1980

Received for publication 26 Jan. 1989. Paper no. 11999 of the Journal Series of the North Carolina Agricultural Research Service, Raleigh, NC 276957643. The use of trade names in this publication does not imply endorsement by the NCARS of the products named, nor criticism of similar ones not mentioned. We gratefully acknowledge the technical assistance of R.R. Horton, Jr. The cost of publishing this paper was defrayed in part by the payment of page charges. Under postal regulations, this paper therefore must be hereby marked advertisement solely to indicate this fact.

'Associate Professor.

${ }^{2}$ Professor. through 1984) at the Horticultural Crops Research Station near Clinton, N.C. $\left(35^{\circ} 1{ }^{\prime} \mathrm{N}\right.$, $78^{\circ} 17^{\prime} \mathrm{W}, 48-\mathrm{m}$ elevation).

The objectives of this study were to compare the ability of the reduced ceiling method and the standard method to predict harvest date of processing and fresh-market cucumbers during 3 years (1984 through 1986) and three seasons (spring, summer, fall) at Clinton, Clayton, and Castle Hayne, N.C. The site in Clayton was the Central Crops Research Station $\left(35^{\circ} 39^{\prime} \mathrm{N}, 78^{\circ} 30^{\prime} \mathrm{W}, 101 \mathrm{~m}\right.$ elevation) and in Castle Hayne it was the Horticultural Crops Research Station ( $34^{\circ} 19^{\prime} \mathrm{N}, 77^{\circ} 55^{\prime} \mathrm{W}, 12-\mathrm{m}$ elevation). The Clinton and Castle Hayne stations are located in the Southern Coastal Plain (Climate Zone 6 of North Carolina). Clayton is in Climate Zone 7, the Central Coastal Plain.

Experimental methods. Plots were hand seeded on raised beds in single rows $1.5 \mathrm{~m}$ apart and $6 \mathrm{~m}$ long. Plots were thinned to $\approx 70,000$ and 50,000 plants/ha for processing and fresh-market cucumbers, respectively. Observed harvest date was determined as that time when the crop averaged $10 \%$ oversized fruits (diameter $>51 \mathrm{~mm}$ for processing and $>60 \mathrm{~mm}$ for fresh-market cucumbers).

Cultivars and breeding lines used were chosen to represent the range of variability available for yield and earliness (Table 1). Standard cultural practices were used for all crops. The soil was treated the October before planting with the nematicide1,2-dichloropropane, 1,3dichloropropene (dichloropropene) at 93 liters $\cdot \mathrm{ha}^{-1}$. Fertilizer $\left(90 \mathrm{~N}-20 \mathrm{P}-74 \mathrm{~K}, \mathrm{~kg} \cdot \mathrm{ha}^{-1}\right)$ was broadcast in the spring before bed formation. At that time, tank-mixed $O, O$-bis(1methylethyl)-S-[2-[(phenylsulfonyl)amino] ethyl]phosphorodithioate] (bensulide) and 2-[(1-naphthalenylamino)carbonyl]benzoic acid (naptalam) were incorporated at rates of 9.9 and $4.5 \mathrm{~kg} \cdot \mathrm{ha}^{-1}$, respectively, to control weeds. Post-plant fertilizer consisted of a sidedress application of $34 \mathrm{~kg} \mathrm{~N} / \mathrm{ha}$. Irrigation was applied using overhead sprinklers as needed to supplement natural rainfall so that each field received a total of $\approx 25$ to $38 \mathrm{~mm}$ of water each week.

Model testing. The average heat unit sum-
Table 1. Cultivars and breeding lines of processing and fresh-market cucumbers used during 3 years to test the heat unit and standard method of harvest prediction.

\begin{tabular}{llll}
\hline & \multicolumn{1}{c}{1984 and 1985 } & & \multicolumn{1}{c}{1986} \\
\cline { 1 - 1 } Processing & Fresh-market & & Processing \\
\hline Addis & Aodai-Nazare & Addis \\
Calypso & Ashley & & Calypso \\
Carolina & Castlehy 2506 & Carolina \\
Castlepik & Coolgreen & & Castlepik \\
Chipper & Cypress & & Chipper \\
Commander & Dasher II & & Clinton \\
Earlipik 14 & Gemini 7 & & Colet \\
Gy 14A & Guardian & & Earlipik 14 \\
Gynomite & Gy 57u & & Fremont \\
Lucky Strike & High Mark II & Gy 3 \\
M 21 & Marketer & Gy 14A \\
National & Marketmore & 76 & Little John \\
Pickling & & \\
Panorama & Marketmore & & M 21 \\
& 80F & & \\
Pennant & Monarch & & Marbel \\
Pikmaster & Pacer & & Pioneer \\
Regal & Palomar & & Regal \\
Score & Poinsett 76 & & Sumter \\
SMR 58 & Slice Mor & Wautoma \\
Spear It & Sprint 440 S & Wis. SMR18 \\
Sumter & Sprint 440 II & WI 1983G \\
Tamor & Straight 8 & WI 2757 \\
Tempo & Verino & W1 5096 \\
\hline
\end{tabular}

Table 2. Average heat unit summation and days from planting to once-over harvest in five seasons of cucumber production (1980-84) at Clinton, N.C. ${ }^{\mathrm{z}}$

\begin{tabular}{lcccccc}
\hline \multirow{2}{*}{$\begin{array}{c}\text { Cucumber } \\
\text { type }\end{array}$} & \multicolumn{3}{c}{ Days to harvest } & & \multicolumn{2}{c}{$\begin{array}{c}\text { Heat unit } \\
\text { summation }\end{array}$} \\
\cline { 2 - 4 } & Mean & Low & High & & ${ }^{\circ} \mathrm{F}$ & ${ }^{\circ} \mathrm{C}$ \\
\hline Processing & 48 & 40 & 54 & & 1125 & 607 \\
Fresh-market & 58 & 50 & 64 & & 1373 & 745 \\
\hline
\end{tabular}

${ }^{\text {zHeat }}$ units calculated using the reduced ceiling method.

Table 3. Mean, standard deviation, minimum and maximum of predicted days from planting to harvest minus actual days for the heat unit and standard methods of prediction for processing and fresh-market cucumbers.

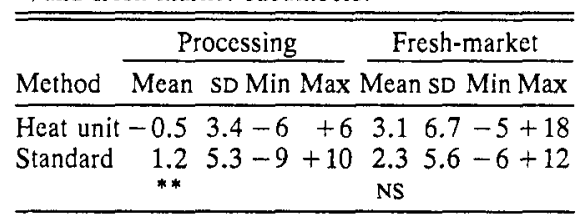

**,NSSignificant at $P=0.01$ or nonsignificant, respectively.

mation for the reduced ceiling method and days from planting to harvest for the two cucumber types are presented in Table 2 . These averages were obtained from the previous study (Perry et al., 1986). Data from Clinton (1984) were used in developing the model, so they were removed from this test. Data from 1986 were only available for processing cucumbers from Clinton, and the Fall 1984 crop at Castle Hayne was destroyed by a hurricane.

Temperature data were collected at the three locations by automatic recording stations using shielded thermistors located $1.5 \mathrm{~m}$ above 
Table 4. Analysis of variance table for predicted days to harvest minus observed days for processing cucumbers.

\begin{tabular}{lcrrc}
\hline Source of & df & $\begin{array}{c}\text { Mean } \\
\text { square }\end{array}$ & $\begin{array}{c}F \\
\text { value }\end{array}$ & $\begin{array}{c}\text { Probability of } \\
\text { a larger F }\end{array}$ \\
\hline Year & 2 & 79.08 & 10.64 & 0.0434 \\
Season & 2 & 30.46 & 4.07 & 0.1398 \\
$\quad$ Error a & 3 & 7.48 & & \\
Location & 2 & 39.12 & 39.12 & 0.1123 \\
Location $\times$ season & 4 & 17.67 & 17.67 & 0.1763 \\
$\quad$ Error b & 1 & 1.00 & & \\
Method & 1 & 32.82 & 57.43 & 0.0001 \\
Method $\times$ location & 2 & 7.15 & 12.51 & 0.0049 \\
Method $\times$ season & 2 & 53.51 & 93.73 & 0.0001 \\
Method $\times$ location $\times$ season & 4 & 1.23 & 2.15 & 0.1773 \\
$\quad$ Error c & 7 & 0.57 & & \\
\hline
\end{tabular}

Table 5. Differences (average over year and seasons) between model-predicted and observed harvest dates using actual observations throughout model run (Actual) and 30 days post-planting plus historical data (Historical).

\begin{tabular}{lccccccc}
\hline & \multicolumn{3}{c}{ Processing } & & \multicolumn{3}{c}{ Fresh-market } \\
\cline { 2 - 4 } Location & Actual & Historical & Difference & & Actual & Historical & Difference \\
\hline Clinton & 3.8 & 3.8 & $0.0^{\mathrm{NS}}$ & & 7.3 & 11.7 & $4.4^{\mathrm{z}}$ \\
Clayton & 2.7 & 2.7 & $0.0^{\mathrm{NS}}$ & & 3.3 & 3.2 & $-0.1^{\mathrm{NS}}$ \\
Castle Hayne & 1.8 & 2.2 & $0.6^{\mathrm{NS}}$ & & 3.6 & 4.8 & $1.2^{\mathrm{Ns}}$ \\
\hline
\end{tabular}

${ }^{2}$ Insufficient data for statistical analysis.

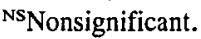

ground. The model was run using two data sets. The first data set was comprised of observed air temperatures for 30 days postplanting and then historical data (1951 through 1980 averages) for the remainder of the season. The rationale behind choosing the 30 day period was that a predictor should provide the grower with adequate lead time to be useful in making decisions, e.g., labor management, field replanting, and equipment allocation. The second data set was comprised entirely of observed air temperatures. Each of these data sets was used separately in the heat unit model until the summation equaled or exceeded the average values in Table 2 .

An analysis of variance was carried out to determine if a significant difference existed between the ability of the model and the standard method to predict harvest. The parameter analyzed was the number of days predicted by the heat unit model minus the observed number and the number predicted by the standard method minus the observed number. A split-split plot design was used with the season as the main plot, location as subplot, and method of prediction (heat unit model, standard method) as sub-sub plot.

The two methods of predicting harvest were significantly different for processing, but not for fresh-market cucumbers (Table 3). For processing cucumbers, the heat unit model was better than the standard method of counting days, since its mean was closer to zero (i.e., closer to the observed) and its standard deviation was smaller. However, significant main effects also resulted from year, indicating that it would be difficult to apply the heat unit model to widely varying environments (Table 4). Significant interactions also existed between method and season, and method and location, i.e., the differences in the two methods of prediction are not the same over all seasons or at each location. However, for a given location and season, a processing cucumber grower could find the heat unit model a better predictor.

Originally, we assumed a decrease in accuracy was introduced in the heat unit model by using 30 days post-planting data followed by historical data to run the model. We felt an assessment of the model using only actual observations compared to the 30 days postplanting plus historical data would demonstrate how much accuracy was lost due to weather variability in the late stage of crop development. It would also show how much could be gained by an accurate 2 - to 4 -week forecast.

However, it was necessary to determine whether the actual observed temperatures did indeed deviate from the historical normals for the period after 30 days post-planting. Historical summaries of climate data are available for North Carolina (U.S. Department of Commerce, 1980-1986). Each year, spring planting was in late April, summer planting in mid-July, and fall planting in early August. Therefore, after using 30 days of actual observations, the historical data were substituted in June for spring crops, midAugust into September for summer crops, and the last 3 weeks in September and first 2 weeks of October for the fresh-market crops of fall.

We found that the actual observations did deviate from the norms (data not presented), causing us to expect accuracy to increase by using only actual observations. However, no significant differences between using only actual observations and substituting historical data after the first 30 days (Table 5) were found for processing or fresh-market cucumbers at any location. Therefore, the model is either flawed or, possibly, the crop development response to temperature decreases as it matures (i.e., temperature has less effect on the rate of crop development during the period in which historical data are used). The latter hypothesis suggests that an earlier stage of development (e.g., flowering) may be better predicted by heat unit summation, but after this stage has been achieved, counting days appears to be just as good.

Any attempt to explain the entire developmental and maturing process of a crop by merely using a temperature model is an oversimplification. Still, these results do show that heat unit modeling has potential for operational applications, although more work is needed.

Air temperature is a good indicator of crop temperature, but other environmental characteristics also influence crop temperature. Atmospheric moisture and its effect on radiation, and wind speed can cause varying differences between air and plant temperature. Therefore, one way to improve the model would be to incorporate such values directly into the model (which would make it expensive and difficult for a grower to use operationally). An alternative would be to develop an adjustment approach, e.g., on cloudy and/ or windy days, it would use air temperature as measured; on sunny days, a predetermined number of degrees would be added to the measured air temperature; and on clear, calm nights, a predetermined number of degrees would be subtracted from the measured air temperature.

\section{Literature Cited}

Perry, K. B., T.C. Wehner, and G.L. Johnson. 1986. Comparison of 14 methods to determine heat unit requirements for cucumber harvest. HortScience 21:419-423.

U.S. Department of Commerce. 1980-1986. Climatological data, North Carolina. vol. 85-91. Natl. Climate Data Ctr., Asheville, N.C. 